length of $9 \cdot 9 \AA$ on one side and 6 contacts in a length of only $7.5 \AA$ on the other, is less, but not much less, efficient. Longer molecules, if they had to attach themselves within a length of $10 \AA$, would either have ono very mobile free end, or else would have to bend around and thus reduce the number of contacts drastically. In either case, they would be easily detachable.

Similarly, the maximum neuromuseular block $(n=10)$ corresponds with two chances of 8 contacts in a length of $15 \AA$.

Increased efficiency of action on cooling is easily understood in terms of numerous van der Waals attachments, since these will be sensitive to thermal vibration, especially of the more mobile methyl groups. A rise of temperature will mean a greater tendency for the attached chains to break away. Although the behaviour in the body will not be precisely the same as in the solid state, yet any mechanism which involves the fastening of molecules into even temporarily fixed positions is not likely to bring into action forces very different from those in the erystal.

Kathleen Lonsdale

H. J. Millefege

Department of Chemistry, University College,

London, W.C.1.

\section{Effect of Spinal Cord Transection on Adrenal 17-Hydroxycorticosteroid Secretion in Response to Insulin Hypoglycaemia}

Adrenal 17-hydroxycorticosteroid (17-OHCS) secretion in response to insulin hypoglycaemia has been evaluated directly in anaesthetized ${ }^{1}$ and unanaesthetized ${ }^{2}$ dogs. As to the mechanism of insulin-induced adrenocortical secretion, Dury ${ }^{3}$ suggested from his experimental results that insulin hypoglycaemia resulted in an increase in adrenal medullary secretion, which inducod the release of adrenocortical hormones. On the other hand, it was claimed by some authors that insulin-induced adrenocortical secretion was not dependent on the sympathoadrenomedullary activity ${ }^{4-6}$. In the experiments of Egdahl ${ }^{7}$ the adrenal medullary response to $E$. coli endotoxin was found to be abolished by the transection of the spinal cord at $\mathrm{C}_{7}$ and the adrenal $17-\mathrm{OHCS}$ secretion in response to endotoxin was not affected by the spinal cord transection. He suggested that the adrenal cortical response to endotoxin was not dependent on the activity of the sympatho-adrenomedullary system. Thus it seems of interest to evaluate directly the adrenal 17 -OHCS secretion in response to insulin in cord-sectionod dogs.

Experiments were done in 3 male mongrel dogs whose dorsal spinal roots $\left(T_{11}-L_{3}\right)$ were cut several weeks beforehand. The transection of the spinal cord at the level of $C_{7-8}$ was performed under sodium pentobarbital $(25 \mathrm{mg} /$ $\mathrm{kg}$ body-wt.) anaesthesia 2 days before the experiments. The adrenal venous blood was collected without anaesthetizing the animals by a modification of the method of Satake, Sugawara, and Watanabe ${ }^{8}$, as was done in our previous studies ${ }^{2,9,10}$. About $18 \mathrm{~h}$ before observation the lumbo-adrenal vein was exposed through the lumbar route and a small glass cannula was inserted into the vein lateral to the gland. The cannula was connected with a small short rubber tube, and both were filled with heparin saline solution. A loop of silk thread was placed loosely around the adrenal vein between the adrenal gland and the postorior vena cava. It was pulled gently at the time of adrenal venous blood collection. The adrenal venous blood was collected twice with a 20 -min interval before insulin injection. Insulin was injected intravenously in a dose of 10 units per $\mathrm{kg}$ body-wt. At 60, 90, and 120 min after injection of insulin the adrenal venous blood collections were also made. Adrenal venous blood was centrifuged immediately after collection and adrenal venous plasma was analysed for 17-OHCS by the Nelson and Samuels ${ }^{11}$ method. The blood sugar was estimated by the method of Somogyi ${ }^{12}$. Since these experiments were performed in July when the temperature in the laboratory was high, the rectal temperature of the animals remained above $38^{\circ} \mathrm{C}$ during the experiment in all cases.

\begin{tabular}{|c|c|c|c|c|}
\hline \multirow{2}{*}{$\begin{array}{c}\text { Body-wt. } \\
(\mathrm{kg})\end{array}$} & \multicolumn{4}{|c|}{$\begin{array}{l}\text { Adrenal 17-hydroxycorticosteroid secretion-rate }(\mu \mathrm{g} / \mathrm{kg} / \mathrm{min}) \\
\text { Before injection }\end{array}$} \\
\hline & & 60 & 90 & 120 \\
\hline $13 \cdot 9$ & $0 \cdot 02-0.03$ & $2 \cdot 78$ & $2 \cdot 64$ & $1 \cdot 36$ \\
\hline $18 \cdot 0$ & $0 \cdot 02-0 \cdot 05$ & 1.55 & 1.51 & 1.62 \\
\hline $19 \cdot 0$ & $0 \cdot 07-0 \cdot 10$ & 0.95 & $0-88$ & 0.58 \\
\hline
\end{tabular}

The blood sugar content before injection was 90-115 $\mathrm{mg} \%$. After injection it decreased markedly, and at the end of observation ( $2 \mathrm{~h}$ after injection) it was measured as $31-33 \mathrm{mg} \%$. Results concerning the adrenal 17-OHCS secretion-rate before and after injection of insulin are shown in Table 1. The secretion-rate before injection of insulin was $0 \cdot 02-0 \cdot 10 \mu \mathrm{g} / \mathrm{kg} / \mathrm{min}$. It inereased markedly after insulin injection. The adrenocortical response to insulin hypoglycaemia was proved not to be materially affected by the spinal cord transection.

TATUzI SUzUKI

Haruhiko Yoshio

KEN-ICHI KUROUJ[ KenJI HiRat

Department of Physiology,

Nagasaki University School of Medicine, Nagasaki, Japan.

${ }^{1}$ Goldfien, A., Zileli, M. S., Despointes, R. H., and Bethune, J. E., Enidotrinology, 62, 749 (1958).

${ }^{2}$ Suzuki, T., Mitamura, T., Zinnouchi, S., and Yamashita, K., Naturkisenschaften, 51, 219 (1964).

${ }^{3}$ Dury, A., Endocrinology, 47, 387 (1950).

Goldon, M. L., Endocrinology, 47, 13 (1950).

' Vogt, M., J. Physiol., 114, 222 (1951).

${ }^{6}$ Kraicer, J., and Logothetopoulos, J., Acta Endocrin., 44, 272 (1963).

" Egdahl, R. H., J. Clin. Invest., 38, 1120 (1959).

${ }^{8}$ Satake, Y., Sugawara, T., and Watanabe, M., Tohoku J. Exp. Med., 8, 501 (1927).

Suzuki, T., Yamashita, K., Kamo, M., and Hirai, K., Endocrinology, 70. 71

${ }^{10}$ Suzuki, T., Hirai, K., Yoshio, H., Kurouji, K., and Yamashita, K., Amer. J. Physiol., 204, 847 (1963).

${ }^{11}$ Nelson, D. H., and Samuels, L. T., J. Clin. Endocrin., 12, 519 (1952).

${ }^{12}$ Somogyi, M., J. Biol. Chem., 160, 69 (1945).

\section{A Series of Compounds Active against Cestodes}

THE following general formula represents a series of chemical compounds effective against cestodes parasitic in the intestinal tract of mammals:<smiles>[R4]Oc1ccc(C(=N)N([R])[R])c2ccccc12</smiles>

These compounds (patent applications pending) are higher members of the elass represented by formula (1) $\left(R, R_{1}=\right.$ alkyl) of which several salts have been propared and tested. Lower members of this class have previously been reported to have local anaesthetic properties ${ }^{1}$.

Determination of comparative activity within the series was carried out in mice against the tapeworms Hymenolepis nana and Oochoristica symmetrica. The most active compounds were then scroened against Taenia pisiformis in dogs. Several showed a high level of activity against this parasite, and the most efficient proved to be 